\title{
Spatial patterns in the retained catch composition of Irish demersal otter trawlers: high-resolution fisheries data as a management tool.
}

\author{
Gerritsen $\mathrm{HD}^{1 *}$, Lordan $\mathrm{C}^{1}$, Minto $\mathrm{C}^{2}$, Kraak SBM ${ }^{3}$ \\ ${ }^{1}$ Marine Institute, Rinville, Oranmore, Co Galway, Ireland \\ ${ }^{2}$ Marine and Freshwater Research Centre, Galway-Mayo Institute of Technology, \\ Dublin Road, Galway, Ireland. \\ ${ }^{3}$ School of Biological, Earth \& Environmental Sciences, University College Cork, \\ Ireland \\ * corresponding author: email: hans.gerritsen@marine,ie; phone: +353 91 387297; \\ fax: +35391387201
}

\begin{abstract}
High-resolution fisheries data from integrated logbook and Vessel Monitoring Systems (VMS) records have revealed a detailed spatial structure in the species composition of the retained catches of the Irish demersal otter trawl fleets. Hierarchical cluster analysis was used to define 8 clusters with relatively homogenous species compositions. These clusters formed 34 distinct spatial regions in the waters around Ireland. Identification of these regions can be useful for a number applications, including spatial stratification of commercial or survey data, defining and characterising fishing grounds for marine spatial planning, evaluation of closed areas and prediction of how fishing effort might be re-allocated following a closure. A casestudy is presented that explores options to reduce cod (Gadus morhua) catches by implementing seasonal closures in two of the 34 regions. Cod are caught by demersal trawlers in a mixed fishery and the catches often exceed the quota, resulting in discarding of marketable fish. Two regions were identified that had relatively low effort and high cod landings. The effects of closing these regions during the first quarter of the year were explored. Cod catches were likely to be reduced by $8-22 \%$ while only 3-9\% of the annual demersal otter trawl effort would be displaced. Whiting catches were also likely to be reduced, the change in catches of some other species depended on the assumed effort displacement.
\end{abstract}

\section{Keywords}

hierarchical cluster analysis (HCA); logbooks; mixed fisheries; spatial management; species composition; VMS

\section{Highlights}

- The detailed spatial structure fisheries data is presented and explored.

- Regions with homogenous species compositions are defined using HCA.

- Potential applications for spatial management of mixed fisheries are examined.

- We explore various scenarios of effort displacement following a spatial closure.

- We estimate the effect of the closure on catches and landings of various species. 


\section{Introduction}

Many aspects of the marine environment are highly heterogeneous in space. The distribution of demersal species can depend on variables like depth, bottom type, hydrological conditions and interactions with fishers, predators and, prey and competitors (e.g. Planque et al., 2011). Historically, fisheries management has not taken account of this fine-scale spatial structure because most data were only available at broad spatial scales. However, in recent years policy developments such as the ecosystem approach to fisheries management (FAO, 2008) and the Marine Strategy Framework Directive (EU, 2008) have driven a demand for fisheries data at a high spatial resolution. These data are also required to evaluate and monitor spatial management measures like marine protected areas or marine reserves (Eastwood et al., 2008; Hillborn et al., 2004) or fine-scale real-time fishing closures (e.g. Dunn et al., 2011; Holmes et al., 2011; Needle and Catarino, 2011). Spatially resolved fisheries data are also required to address the growing extent and diversity of ocean uses beside fisheries, many of which are incompatible with each other (e.g. recreation, wind and wave power, minerals extraction, aquaculture, shipping, conservation). These ocean uses are increasingly managed by prohibiting or permitting them in specific areas.

Effective spatial management requires appropriate boundaries to be drawn around the areas that are to be managed as mismatches between the scale of the resources and of their assessment and management can be a cause of management failure in fisheries (Lorenzen et al., 2010). In practice, however, management areas are often drawn along straight lines of latitude and longitude at scales of thousands of square nautical miles, for example stock assessment areas (ICES, 2011a), Total Allowable Catch (TAC) management areas (EC, 2011) or seasonal closures (e.g. the Trevose closure: Annex III section 6.2 of EC 2009) although some closed areas follow more natural boundaries (e.g. the Porcupine Bank closure: Article 13 of EC 2011).

Fisheries management is often further complicated by the fact that many stocks have overlapping spatial distributions and are caught together in mixed fisheries. In Europe, fish stocks have traditionally been assessed and managed on a single-species basis. However, single-species quota tend to lead to sub-optimal use of fisheries resources (Rätz et al., 2007; Ulrich et al., 2011) because when quota for one or more species are exhausted, fishing may continue and this will lead to discarding of over-quota catches and fishing mortalities that are above management targets. Alternatively, if the fishery would be closed once the landings of the first species have reached their quota, then the fishing mortality of the other species in the same fishery will be below target, leading to loss of potential revenue.

Ulrich et al. (2011) have developed a tool, Fcube, which is currently used in the ICES Working Group on mixed-fisheries advice for the North Sea (ICES, 2010; ICES, 2011b). Fcube can estimate what the likely catches of the various species in the mixed assemblage will be under a variety of management scenarios and assumptions about fishers' behaviour in relation to set quotas. The approach accounts for differences in catchabilities between métiers (types of activity) within fleets (groups of vessels) and the single-species TAC settings. Fcube does not explicitly take the spatial element of catch composition into account.

Another way of managing mixed fisheries is through taxes on over-quota landings (Holland, 2003; Marchal et al., 2009) or by varying the cost of fishing by area, depending on the expected catch or landings per unit effort (cpue/lpue) (Kraak et al., 2012). These approaches allow fishers to optimise their profits by avoiding or minimising taxes or costs of fishing. If the scheme is well-designed, this behaviour 
should result in fishing mortalities that are closer to management targets than a TAC system alone.

The approach proposed by Kraak et al. explicitly takes the spatial and temporal variation in lpue of fish species into account. This kind of fisheries data has become available at fine spatial scales since the introduction of Vessel Monitoring Systems (VMS) which automatically collect positional data from fishing vessels. These positional data can be linked to national logbook landings data (e.g. Gerritsen and Lordan, 2011) to obtain spatially resolved fisheries data. These data can be an important tool for understanding and managing mixed fisheries if they can be presented in a usable form.

One of the problems that occurs when dealing with spatially resolved data is the large numbers of variables involved (location, time, species composition, fishing effort, gear parameters). One way of reducing the complexity of the dataset is by finding regions with similar properties that are stable over time. In the current paper we propose a method of defining regions with homogenous species compositions in the retained catches ${ }^{1}$. Such regions will be useful for a large number of applications, including: (1) stratification for sampling of commercial landings or other surveys; (2) stratification of commercial lpue data so these data become less sensitive to changes in the spatial distribution of the fleet; (3) defining and characterising fishing grounds for example for the purpose of marine spatial planning; (4) providing natural boundaries for closed areas or effort management areas; (5) predicting how changes in spatial distribution of the fleet might affect the composition of the landings and / or discards. We will illustrate the latter two applications in a case study. The other applications will be considered in more detail in the discussion section.

In our case study we will investigate a situation where fisheries managers impose a seasonal closure in two regions with high cod cpue in order to reduce cod (Gadus morhua) catches in the Celtic Sea (the region to the south of Ireland and north of Biscay). These cod are caught as part of a mixed fishery and there is currently little or no incentive to avoid over-quota catches of cod, resulting in discarding of marketable fish. We will investigate a number of scenarios of effort displacement following this hypothetical closure. By applying the changes in effort to cpue estimates in each region we estimate the changes in catches and landings of cod and other species caught by the Irish demersal otter trawl fleet. We do not expect to precisely predict the actual effort displacement but by examining a range of possibilities, we can quantify how sensitive the results are to the various effort displacement assumptions.

\section{Methods}

Since 2005, all European Community (EC) fishing vessels of $\geq 15 \mathrm{~m}$ in overall length have to be fitted with VMS transponders which transmit their position at least every $2 \mathrm{~h}$ whilst at sea (EC, 2003). Skippers of EC vessels of $\geq 10 \mathrm{~m}$ in overall length are also required to record their retained catches on a daily basis in standard logbooks (EEC, 1983). VMS and logbook data are available to the Marine Institute for the period 2006-2009. Gerritsen and Lordan (2011) have described a method to integrate VMS data with the retained catch data recorded the logbooks. Discard data are available for the period 1995-2010; however, only around 1\% of all fishing trips had discard observers on board (Anon, 2011; Lordan et al., 2011).

\footnotetext{
${ }^{1}$ Throughout this document the terms 'retained catch' and 'landings' are used interchangeably. The term 'landings' can be confusing when discussed in a spatial or temporal sense as the landings generally take place in port at the end of a trip while the catches take place at sea throughout the trip. Only the retained catches are landed but most catches also have a discarded component
} 
Following the method described by Gerritsen and Lordan (2011), each VMS location of Irish demersal otter trawlers was allocated an effort value, which is the time since the previous VMS record (generally 2 hours). The VMS data were filtered for vessel speeds between 1.5 and 4.5 knots in order to select records corresponding to fishing activity. In a small proportion of cases $(<3 \%)$ the vessel speed was not transmitted, for these records the vessel speed was estimated from the distance and time interval since the previous record. Gerritsen and Lordan (2011) have shown that vessel speed can distinguish fishing activity with an accuracy of $88 \%$ and most errors (both falsepositive and false-negative) occurred around the start and end of fishing operations. The daily retained catch data were allocated equally to the 'fishing' VMS records for each vessel and date. The resulting retained catch and effort data were aggregated to the grid of $0.10^{\circ}$ longitude $* 0.05^{\circ}$ latitude. This grid size was chosen as a compromise between spatial resolution and the number of data points per grid cell. Any grid cells with fewer than 5 VMS 'fishing' records or less than $100 \mathrm{~kg}$ total retained catch were omitted from the analysis. Data from all available years (20062009) were combined for the initial analysis.

A hierarchical cluster analysis was performed on the gridded data to identify areas with similar species compositions. The 10 most abundant species and species categories in the landings were included in the cluster analysis (Table 1). Some of these were grouped at a higher taxonomical level (rays/skates and deepwater species). These 10 species categories accounted for $90 \%$ of the total demersal landings, all other species were grouped in an $11^{\text {th }}$ category ('other'). The retained catch weights by species category in each grid cell were converted to proportions. Next, a dissimilarity matrix was constructed by calculating the Euclidian distance between the cells using the proportions of the 11 species categories to define their location in 11dimensional Euclidian space. A hierarchical cluster analysis, using Ward's minimum variance clustering algorithm (Gordon, 1987) was then applied to this matrix. The spatial distance between the grid cells was not taken into account in the cluster analysis, so any spatial patterns that emerge from the analysis are the result of similarities in the retained catch composition of neighbouring cells.

The most appropriate number of clusters was chosen using expert knowledge: if the number of clusters is too low, then species that occur in distinct habitats will be grouped together but if the number of clusters is too high, then similar fisheries will be assigned to different clusters. After deciding on an appropriate number of clusters, the spatial distribution of these clusters was mapped and regions with cells of the same cluster that were contiguous (or nearly contiguous) were defined by manually drawing polygons around these regions. In areas where the boundaries were illdefined, depth contours and information on bottom type were used to improve the boundary definition. Because one species composition cluster might occur on two or more spatially distinct fishing grounds, there are a larger number of regions than clusters.

In order to describe the variability in the species compositions within each of the clusters, a centred logratio transformation was applied to the proportions of the species composition in each cell and variability was calculated from the sum of the trace of the covariance matrix of the transformed data (Aitchison, 2001). Any proportions with zero values were dealt with by multiplicative imputation (replacing zero values with a small positive value). The replacement value was taken as the smallest non-zero value, multiplied by a given value (delta). We performed a sensitivity analysis for a range of values for delta. Aitchison (1986) suggests a range of $0.2-2.0$ times the smallest non-zero value. The resulting variance varied with delta 
(by around 25\%); however, the variance estimate of each cluster relative to the others remained consistent for all values of delta. Therefore the variance estimates should only be interpreted in a relative way only. We arbitrarily chose a delta value of 0.55 for the final analysis (this is the mid-point of the range suggested by Aitchison). Variability over time was estimated in a similar way to the variability between grid cells. In this case, the species compositions in each of the clusters were estimated for each month of the time series (the data were re-extracted on a monthly basis (48 months); data from all grid cells within each cluster were combined). The variance between months was then analysed in the same way as the variance between the grid cells.

For the purpose of the case-study, the retained catches and effort in each region were extracted from the integrated VMS and logbook databases by matching the VMS positional data to the regional polygons that were defined from the cluster analysis (using the R function "inout()" from the "splancs" library). The estimated discard weights and effort on the observer trips in each region were also matched to these regions, based on the location of the mid-point of each sampled haul. Discard data from all available years (1995-2010) were combined due to the relative scarcity of the data. Lpue and fishing effort were estimated for each region, year and quarter. Dpue (discards per unit effort) were also estimated by region but for all years combined. Cpue was estimated by adding the quarterly lpue estimates to the dpue estimates from all years. This requires the assumption that dpue does not change over time. This is obviously an over-simplification but the discard data were too sparse to allow temporal stratification. This approach will give us more information than landings alone although the catch data will necessarily be imprecise.

We will investigate a situation where fisheries managers impose a seasonal closure of a number of regions to reduce effort in areas with high cod cpue. We analyse a number of effort displacement scenarios under the assumption that the total effort will remain constant. The following three displacement scenarios will be examined: The first scenario assumes that the effort in all regions outside the closed areas will increase in proportion to the existing effort in those regions. This is the simplest and probably least realistic scenario. The second scenario assumes that the effort from the closed regions will be displaced to nearby regions ( $<120 \mathrm{~nm}$ away) belonging to the same clusters. This might be a more realistic scenario, providing suitable regions of the same cluster are available. The third scenario uses the existing distribution of effort of the affected vessels to predict where these vessels will be displaced to (most vessels will have a track record of effort outside as well as inside the closed area). Under this scenario, the affected vessels will increase their effort in the regions outside the closed area in proportion to their existing effort in those regions. This is probably the most realistic of the three scenarios. For all scenarios, we are interested in the catches and landings that would have occurred if the effort was displaced according to each of the scenarios. We estimated these catches and landings from the existing cpue and lpue in each of the regions, multiplied by the fishing effort in each region. This requires a further three assumptions: (1) the increased effort outside the closed areas is small enough not to affect the cpue/lpue of any of the species; (2) skippers of displaced vessels match the fishing and discarding practices to those already present in each of the areas they are displaced to and will achieve the same lpue/cpue as the existing vessels in these areas; (3) the distribution of effort outside the closed season remains unchanged. We acknowledge the scenarios presented here over-simplified; however, they serve simply to illustrate the approach and can be 
improved by adding more complexity, which would be outside the scope of the present work.

All analyses were performed using R 2.14.1 (R-Development-Core-Team, 2011). The boundary polygons were created using Quantum GIS 1.6.0 (http://qgis.org/)

\section{Results}

The species composition of the retained catch shows considerable spatial structure (Figure 1). In some areas the species composition changes abruptly with changes in depth or bottom type, but in other areas a gradual change in the species composition occurs. Each of the cells shown in Figure 1 corresponds to one row of input data for the cluster analysis. The cluster dendrogram is shown in Figure 2. The spatial distribution of the clusters was examined by cutting the dendrogram at various heights, resulting in between 4 and 12 clusters (data not shown). It was considered that the most appropriate number of clusters was 8. Figure 2 shows that if the dendrogram was cut higher (resulting in 7 clusters), the rays cluster would have been merged with the mixed cluster. Because these fisheries are known to be distinct this was considered undesirable. Cutting the dendrogram lower would result in 9 or more clusters which were increasingly less well-defined in space.

The spatial variability in the species composition between the grid cells of the 8 clusters appears to be relatively low (judging by the spread of the data shown in Figure 3a). The most variable cluster was the nephrops mixed cluster: the total variability (totvar) of the log-ratio transformed data was 101.9 (the absolute value is difficult to interpret; it is intended as a measure relative to the other clusters). The proportion of hake was particularly variable in this cluster (ranging from $0 \%$ to $89 \%$ of the retained catch). The least variable cluster was the whiting cluster (totvar = 32.6).

The variability in the species composition between the 48 months of the time-series is shown in Figure 3b. Variability over time is generally lower than the variability between the grid cells, except for the deep cluster. During the period of the study, the Irish deepwater fishery declined strongly as the target species were depleted, which might explain the greater variability over time for this cluster. The ray cluster also has reasonably high variability in both space and time. However, both the deep and ray clusters have a very distinct species composition, so this variability is unlikely to present problems for the analysis. The time series is quite short and long-term variability might be considerably larger and it may be necessary to revise the regions identified here from time to time.

There was a remarkable amount of spatial contiguity in the clusters (Figure 4). This is noteworthy because the location of the grid cells was not taken into account in the cluster analysis. Boundaries were drawn manually around regions with cells of the same cluster (Figure 4). The resulting regions were given names of main fishing grounds or geographical features in order to identify them. The cells of the Deep cluster were not contiguous in some places, but it was decided to include all these into a single region. Depth contours were used to determine the boundaries of this region in areas where data was sparse. In the Smalls region (to the south-east of Ireland), the Nephrops and Nephrops-mixed clusters were merged as these correspond to a single Nephrops fishery taking place on a well-defined mud patch. Similarly, small and spatially distinct fishing grounds like Blackstones and Cape (to the north of Ireland) were also defined as single regions even though they contained cells from a number of different clusters. 
Table 2 gives some summary statistics for each of the 34 regions. The Deep region stands out as having a relatively large surface area (11\% of the total fished area) with very low effort $(0.6 \%)$ and high landings relative to the effort $(2.0 \%)$. For the other regions the percentage of the total effort was similar to the percentage of the total landings (within a factor of 2). The Smalls region had the highest effort (13\%) but only accounted for $2 \%$ of the total surface area The Irish Sea and Aran areas also had much higher effort than might be expected for their size. These three regions are the main areas where Nephrops are targeted, and together accounted for $30 \%$ of the effort and $34 \%$ of the landings but only $4 \%$ of the total area.

The highest quarterly cod landings and lpue were observed in the Nymphe and Galley regions: both had consistently high landings during the first quarter of the year. The effort in the Nymphe and Galley regions during quarter 1 accounted for 3-9\% of the annual effort in all regions while 14-28\% of the annual Irish demersal otter trawl cod landings were taken in those areas during quarter 1. For our case study we will investigate the effects of closing these two regions during the first quarter of the year. This would displace a relatively small amount of effort from an area with relatively large cod landings.

In order to investigate how this closure might have affected the catches of cod and other species, had it been in place for any of the years 2006-2009, we examined three effort displacement scenarios. Under scenario 1, the displaced effort will be distributed over all regions outside the closed regions during quarter 1 . The second scenario assumes that the effort will be displaced only to nearby regions belonging to the same clusters as the closed regions, namely: Erris, Blaskets and Moher. Other regions of the haddock-mix and whiting clusters were more than $120 \mathrm{~nm}$ from the closed regions. The third scenario is based on the distribution of effort of the vessels that have fished in the Nymphe and Galley regions during quarter 1. There were 4 vessels that only fished in the closed regions (and nowhere else). For these, the average effort distribution of the other 166 vessels was used. This resulted in effort mainly being displaced to the neighbouring regions: Mizen (18\%); Smalls (15\%); Labadie2 (11\%); Cork (9\%); Labadie1 (9\%); StGeorge (8\%) as well as to some regions further away: Stanton1 (9\%); Erris (8\%) and other regions (totalling 15\%).

Figure 5 shows the expected changes in the catches and landings for each of the species classes that would have resulted from the change in effort distribution in the 3 scenarios. All scenarios resulted in a significant reduction in cod catches and landings in all years (between 8 and 22\%). There was very little difference between the reduction in catch and landings, suggesting the two are well correlated. Whiting catches and landings would also have been reduced under all scenarios (between 2 and 16\%) because landings from the Nymphe region are dominated by whiting. Scenarios 1 and 3 resulted in minor changes in the catches and landings of the other species. Scenario 2 resulted in strongly increased catches and landings of hake, saithe and rays in most years and increased landings of deepwater species and haddock in some years. This is the result of the assumption, under this scenario, that the effort will shift mainly to the Erris region which has higher cpue and lpue for these species than Labadie and Galley.

\section{Discussion}

The results have shown that there is a strong spatial structure in the species composition of the retained catches of Irish demersal otter trawlers. It should be noted that the spatial patterns shown here are not intended to describe the actual distribution 
or abundance of these species, it is simply a reflection of the retained catches and is influenced by catchability, targeting practices and discarding patterns.

The clustering algorithm identified clusters that were spatially discrete even though the location of the grid cells was not taken into account in the cluster analysis. Therefore it was possible to identify a number of regions that were largely objectively defined i.e. requiring only a small amount of expert interpretation. For regions with a patchy distribution (e.g. the deep cluster), additional information like depth contours or bottom type were needed to draw appropriate boundaries.

The current analysis is based on the proportion of the species caught (and retained) in each grid cell. An alternative approach might have been to use the lpue of each species in the cluster analysis. However, this approach would have some disadvantages over using proportions; specifically, proportions are less sensitive to changes in lpue. For example, if the landings of a certain species make up 50\% of the total landings in one year and in the next year the lpue of that species doubles relative to the other species, then the landings proportion will (obviously) not double to $100 \%$, but instead it will only increase from $50 \%$ to $67 \%$. This effect stabilises the species composition over time despite changes in lpue (particularly for species that are relatively abundant).

The variability in the species composition, both in space (between grid cells) and time (between months) was reasonably low. One would expect the variability between cells to be minimised by the clustering algorithm, however no temporal data were used in the cluster analysis (all data from the full time series were combined) and therefore the relatively low variability over time is an indication that the clusters are quite stable. Obviously changes in relative species abundance and migration patterns will influence the species composition over time, but this does not appear to be a major factor in the overall species composition of each cluster, at least during the time series investigated here.

The definition of regions with similar species compositions provides management with a tool to explore different scenarios of effort displacement and as such can be used to evaluate the possible effects of closures or effort restrictions in certain areas. The actual outcome of such spatial management will depend not only on how fishing effort will be displaced but also on the cpue and lpue in each of the regions. In the current case the lpue was known because the fishery had already taken place (and cpue was assumed to be invariable over time). In order to predict the effect of future closures, a recent average lpue or cpue might be used, perhaps refined by information on abundance trends from stock assessment forecasts or sentinel fisheries.

The retained catch and effort data used here are census data and are therefore known without sampling error, but there will be some errors associated with the collection and entry of the data. Additionally, the trawl locations of the retained catches are inferred from the VMS positional data and while the retained catches are reported on a daily basis, the time interval for VMS transmissions is generally 2-hourly. As a vessel may travel a considerable distance within a day, there is some uncertainty around the actual location where the catches of each species were taken. However if one assumes that the species composition of the retained catches generally does not change much within a day, this uncertainty may be quite low. Data from observer trips on Irish demersal otter trawlers (> 2000 days) suggests that the species composition between hauls made on the same day is indeed quite stable: for the 10 species classes analysed here, the proportion of each these species changed less than $10 \%$ between hauls on the same day in $83 \%$ of the cases. 
The sampling error of the discard data is likely to be considerable due to the relatively small sample numbers (Table 2 shows the number of trips and the number of hauls sampled in each region). For this reason, the expected changes in landings as well as catches are presented (Figure 5). In general, the changes in landings are very similar to the changes in catches, suggesting that the two correlate well.

A number of assumptions were made in the displacement scenarios. Firstly overall effort was assumed to remain unchanged. This might seem unrealistic if fuel costs are much higher for vessels that are displaced to other regions. However vessels do not necessarily have to travel longer distances because in many cases fishers have the option to land in ports other than their 'home' port. It was also assumed that the increased effort outside the closed areas does not reduce the lpue in those regions and that the reduced effort inside the closed areas does not increase the lpue there. This is, of course, an over-simplification which could be addressed by a more complicated effort displacement model that includes data on stock size, fishing mortality etc. A further assumption requires that when effort is displaced, the skippers will adapt their fishing practices to the existing practices in the region that they are displaced to. This seems like a reasonable assumption: for example, one would expect a skipper who is displaced from a monkfish region to a Nephrops region to start using gear with a smaller mesh size. Finally, we assumed that fishers would not increase their effort in the closed area outside the closed season. This may be an unrealistic expectation but it is possible to enforce this by not allowing an effort increase in these areas if this is considered undesirable. The case study presented here is a much simplified version of reality; however, by examining a range of scenarios, one might get an insight into the possible range of outcomes following a closure, this is something that has always been very difficult to predict (e.g. Davie and Lordan, 2011b).

None of the scenarios are very sophisticated (i.e. fisher's behaviour is not explicitly modelled) and with additional (e.g. economic) information they can be improved considerably. The main purpose of evaluating these scenarios was to illustrate the principle and to provide a range of possible effects on the catches of the main species involved in the Irish demersal trawl fishery. All scenarios resulted in a significant reduction of cod catches in all years; therefore, one might be confident that the closure will achieve this goal. However, under scenario 2 the catches of some species were likely to increase. This might be acceptable, but it might also contravene other management objectives, for example if the TAC of these species was already restrictive. In any case, this approach will provide management with a range of possible outcomes that can be evaluated.

The case study shows that the regions that were defined here may be useful to identify areas with high catch rates of quota-restricted species, such as cod, enabling the fleet to be directed away from these areas. This is particularly relevant for fisheries targeting whitefish because there is currently no incentive to avoid by-catches (and resulting discards) over-quota fish. Although these fisheries may target certain species, considerable by-catches of other species are unavoidable. If there were a number of other species for which the quota are restrictive, a larger number of regions would need to be closed, perhaps for a longer period, to achieve similar reductions in fishing mortality.

Other than the examples illustrated in our case-study, the approach taken here in defining the areas has a range of alternative applications. Our approach is in many ways analogous to the approach taken to define métiers in other studies (e.g. Davie and Lordan, 2011a). These metiers are used to stratify sampling designs. While some metier definitions include a broad geographic component like ICES Divisions, EU- 
wide agreed metier definitions (EC, 2010) are based only on gear, mesh and target species (with no geographic component). Therefore it is possible that within a single metier fishing takes place in two or more distinct fishing grounds with very different population parameters. This may be particularly problematic if data from different countries (with different sampling designs) are combined. If the current analysis would be extended to include international data and once VMS data become available to fisheries institutes in real-time, it would become possible to design a sampling scheme around the regions defined here.

The regions identified in the current analysis could also be used to inform trawl survey design: characterisation of regions with similar species compositions can improve survey stratification (e.g. Dimech et al., 2008). Because the commercial fleet has a much more detailed spatial and temporal coverage than any trawl survey, species composition data from the commercial fishery have the potential to greatly improve trawl survey stratification.

The regions defined here can also be used to spatially stratify commercial lpue estimates: because effort is not distributed evenly in space, lpue estimates are sensitive to changes in the spatial distribution of effort. Failure to account for the spatial dimension can bias lpue trends. For example: if vessels move to a region with high densities of monkfish, the overall lpue of monkfish will increase, even if their abundance does not (e.g. Gerritsen and Lordan, 2011). Stratifying the data by the regions defined here can reduce this problem and allow more commercial data to be used in assessments. This is essentially the same approach as the stratified random sampling design that is commonly used for surveys (Cochran, 1977). Because a stratified lpue estimate will not be biased by changes in effort between regions, it is more likely to reflect stock abundance. The time-series of integrated VMS and logbook data is currently insufficiently long to apply this approach in a meaningful way but the concept is explored in more detail in other publications (Gerritsen and Lordan, 2011; ICES, 2011c).

Finally, marine spatial planning and management increasingly extends beyond fisheries and there are increasing numbers of competing and often mutually exclusive needs vying for use of a limited marine resource. The current analysis can be used to clearly characterise fishing grounds. It can also provide a better understanding of which vessels and fleets will be affected and how fishing effort might be displaced by planning proposals. This type of data is critical to inform planning and impact assessment on various proposals (e.g. oil and gas exploration, wind farms, marine protected areas, aggregate extraction, etc.)

\section{Conclusion}

The current analysis has shown that it is possible to objectively identify regions with homogenous species compositions in space and time (at least in the short term). These regions can be used to evaluate how fishing effort may be re-allocated following a closure and how this will influence the catches and landings. The definition of these regions also has a number of other possible applications in fisheries science. The solution to the key problem of mixed-fisheries management, i.e. how to achieve maximum sustainable yield for a range of species simultaneously while reducing discards, requires a detailed knowledge of the abundance, dynamics and vulnerability of species both in space and time and the current results contribute some progress towards this goal. 


\section{Acknowledgements}

We thank the Irish Naval Service for supplying the VMS data and the Sea-Fisheries Protection Authority for supplying the logbook data. All VMS data were aggregated to a level that did not compromise the confidentiality of individual vessels. Thanks to Sarah Davie for her constructive comments on earlier versions of the manuscript.

\section{References}

Aitchison, J., 1986. The statistical analysis of compositional data. Chapman and Hall, London.

Aitchison, J., 2001. Simplicial Inference. In: Viana, M.A.G., Richards, D.S.P.s (Eds.), Algebraic methods in statistics and probability. American Mathematical Society, Providence, pp. 1-22.

Anon, 2011. Atlas of Demersal Discarding. Scientific Facts and Potential Solutions. Marine Institute / Bord Iascaigh Mhara, Galway, p. 82pp.

Cochran, W.C., 1977. Sampling Techniques. John Wiley \& sons, New York.

Davie, S., Lordan, C., 2011a. Definition, dynamics and stability of métiers in the Irish otter trawl fleet. Fish Res 111, 145-158.

Davie, S., Lordan, C., 2011b. Examining changes in Irish fishing practices in response to the cod long-term plan. ICES J. Mar. Sci. 68, 1670-1678.

Dimech, M., Camilleri, M., Hiddink, J.G., Kaiser, M.J., Ragonese, S., Schembri, P.J., 2008. Differences in demersal community structure and biomass size spectra within and outside the Maltese Fishery Management Zone (FMZ). Sci. Mar. 72, 669-685. Dunn, D.C., Boustany, A.M., Halpin, P.N., 2011. Spatio-temporal management of fisheries to reduce by-catch and increase fishing selectivity. Fish and Fisheries 12, 110-119.

Eastwood, P.D., Meaden, G.J., Nishida, T., Rogers, S.I., 2008. Understanding and managing marine fisheries with the aid of a digital map. In: Payne, A., Cotter, J., Potter, T.s (Eds.), Advances in fisheries science: 50 years on from Beverton and Holt. Wiley-Blackwell, p. 568pp.

EC, 2003. Commission Regulation (EC) No.2244/2003 of 18 December 2003 laying down detailed provisions regarding satellite-based Vessel Monitoring Systems. Official Journal of the European Union L 333, 17-27.

EC, 2009. Council Regulation (EC) No 43/2009 of 16 January 2009 fixing for 2009 the fishing opportunities and associated conditions for certain fish stocks and groups of fish stocks, applicable in Community waters and, for Community vessels, in waters where catch limitations are required. Official Journal of the European Union L 22/1. EC, 2010. Commission decision of 18 December 2009 adopting a multiannual Community programme for the collection, management and use of data in the fisheries sector for the period 2011-2013. Official Journal of the European Union 2010/93/EU, 71 pp.

EC, 2011. Council Regulation (EU) No 57/2011 of 18 January 2011 fixing for 2011 the fishing opportunities for certain fish stocks and groups of fish stocks, applicable in EU waters and, for EU vessels, in certain non-EU waters. Official Journal of the European Union L 24/1.

EEC, 1983. Commission Regulation (EEC) No 2807/83 of 22 September 1983 laying down detailed rules for recording information on Member States' catches of fish. Official Journal of the European Union L 276, 1-18. EU, 2008. Directive 2008/56/EC of the european parliament and of the council of 17 June 2008 establishing a framework for community action in the field of marine 
environmental policy (Marine Strategy Framework Directive). Official Journal of the European Union L 164/19, 22pp.

FAO, 2008. Fisheries management. 2. The ecosystem approach to fisheries. 2.1 Best practices in ecosystem modelling for informing an ecosystem approach to fisheries., FAO Fisheries Technical Guidelines for Responsible Fisheries. No. 4, Suppl. 2, Add. 1. FAO, Rome, p. 78pp.

Gerritsen, H.D., Lordan, C., 2011. Integrating Vessel Monitoring Systems (VMS) data with daily catch data from logbooks to explore the spatial distribution of catch and effort at high resolution. ICES J. Mar. Sci. 68, 245-252.

Gordon, A.D., 1987. A review of hierarchical classification. JSTOR 150, 119-137.

Hillborn, R., Stokes, K., Maguire, J.J., Smith, T., Botsford, L.W., Mangel, M., Orensanz, J., Parma, A., Rice, J., Bell, J., Cochrane, K.L., Garcia, S., Hall, S.J., Kirkwood, G.P., Sainsbury, K., Stefansson, G., Walters, C., 2004. When can marine reseves improve fisheries management? Ocean \& Coastal Management 47, 197-205. Holland, D.S., 2003. Integrating spatial management measures into traditional fishery management systems: the case of the Georges Bank multispecies groundfish fishery. ICES Journal of Marine Science: Journal du Conseil 60, 915-929.

Holmes, S.J., Bailey, N., Campbell, N., Catarino, R., Barratt, K., Gibb, A., Fernandes, P.G., 2011. Using fishery-dependent data to inform the development and operation of a co-management initiative to reduce cod mortality and cut discards

10.1093/icesjms/fsr101. ICES Journal of Marine Science: Journal du Conseil.

ICES, 2010. Report of the Working Group on Mixed Fisheries Advice for the North Sea (WGMIXFISH). 31 August - 3 September 2010. ICES Headquarters, Copenhagen, Denmark, p. 93pp.

ICES, 2011a. Report of the Working Group for the Celtic Seas Ecoregion (WGCSE). ICES, Copenghagen, Denmark.

ICES, 2011b. Report of the Working Group on Mixed Fisheries Advice for the North Sea (WGMIXFISH). 29 August - 2 September 2011.

ICES, 2011c. Workshop on the utility of commercial CPUE and VMS data in assessments (WKCPUEEFORT). Copenhagen.

Kraak, S.B.M., Reid, D.G., Gerritsen, H.D., Kelly, C.J., Fitzpatrick, M., Codling, E.A., 2012. 21st century fisheries management: A spatiotemporally explicit tariffbased approach combining multiple drivers and incentivising responsible fishing. ICES J. Mar. Sci. 69, 590-601.

Lordan, C., Ó Cuaig, M., Graham, N., Rihan, D., 2011. The ups and downs of working with industry to collect fishery-dependent data; the Irish experience. ICES J. Mar. Sci. 68, 1670-1678.

Lorenzen, K., Steneck, R.S., Warner, R.R., Parma, A.M., Coleman, F.C., Leber, K.M., 2010. The spatial dimensions of fisheries: putting it all in place. Bull. Mar. Sci. 86, 169-177.

Marchal, P., Francis, C., Lallemand, P., Lehuta, S., Mahévas, S., Stokes, K., Vermard, Y., 2009. Catch-quota balancing in mixed-fisheries: a bio-economic modelling approach applied to the New Zealand hoki (Macruronus novaezelandiae) fishery. doi:10.1051/alr/2009033. Aquat. Living Resour. 22, 483-498.

Needle, C.L., Catarino, R., 2011. Evaluating the effect of real-time closures on cod targeting. ICES J. Mar. Sci. Advance Access doi: 10.1093/icesjms/fsr092 First published online: June 13, 2011.

Planque, B., Loots, C., Petitgas, P., Lindstrøm, U., Vaz, S., 2011. Understanding what controls the spatial distribution of fish populations using a multi-model approach.

Fisheries Oceanography 20, 1-17. 
R-Development-Core-Team, 2011. R: A language and environment for statistical computing. R Foundation for statistical Computing, Vienna, Austria. ISBN 3-90005107-0, URL http://www.R-project.org.

Rätz, H.-J., Bethke, E., Dörner, H., Beare, D., Gröger, J., 2007. Sustainable management of mixed demersal fisheries in the North Sea through fleet-based management - a proposal from a biological perspective 10.1093/icesjms/fsm030. ICES Journal of Marine Science: Journal du Conseil 64, 652-660.

Ulrich, C., Reeves, S.A., Vermard, Y., Holmes, S.J., Vanhee, W., 2011. Reconciling single-species TACs in the North Sea demersal fisheries using the Fcube mixedfisheries advice framework. ICES J. Mar. Sci. Advance access published May 9, 2011.

\section{Table}

Table 1. The 10 most common species classes in the catches which were used in the cluster analysis and their contribution to the landings. The species code refers to the code used in Table 2 and Figures 1, 3 and 5.

\begin{tabular}{|c|c|c|c|}
\hline Code & Common name & Scientific name & Landings \\
\hline cod & $\operatorname{cod}$ & Gadus morhua & $3 \%$ \\
\hline deep & all deepwater species & $\begin{array}{l}\text { Mostly Phycis blennoides, } \\
\text { Heliocolenus dactyloptreus, } \\
\text { Apogonidae, Coryphaenoides } \\
\text { rupestris, Aphanopus carbo and } \\
\text { Lepidopus caudatus }\end{array}$ & $4 \%$ \\
\hline had & haddock & Melanogrammus aeglefinus & $10 \%$ \\
\hline hke & hake & Merluccius merluccius & $5 \%$ \\
\hline meg & megrim & $\begin{array}{l}\text { Lepidorhombus whiffiagonis and } \\
\text { L. boscii }\end{array}$ & $7 \%$ \\
\hline mon & monkfish & $\begin{array}{l}\text { Lophius piscatorius and } L . \\
\text { budegassa }\end{array}$ & $14 \%$ \\
\hline nep & nephrops & Nephrops norvegicus & $30 \%$ \\
\hline pok & saithe & Pollachius virens & $2 \%$ \\
\hline ray & all rays and skates & $\begin{array}{l}\text { Generally not identified to species } \\
\text { level in the logbooks database }\end{array}$ & $4 \%$ \\
\hline whg & whiting & Merlangius merlangus & $12 \%$ \\
\hline other & all other dermersal species & & $10 \%$ \\
\hline
\end{tabular}


Figures

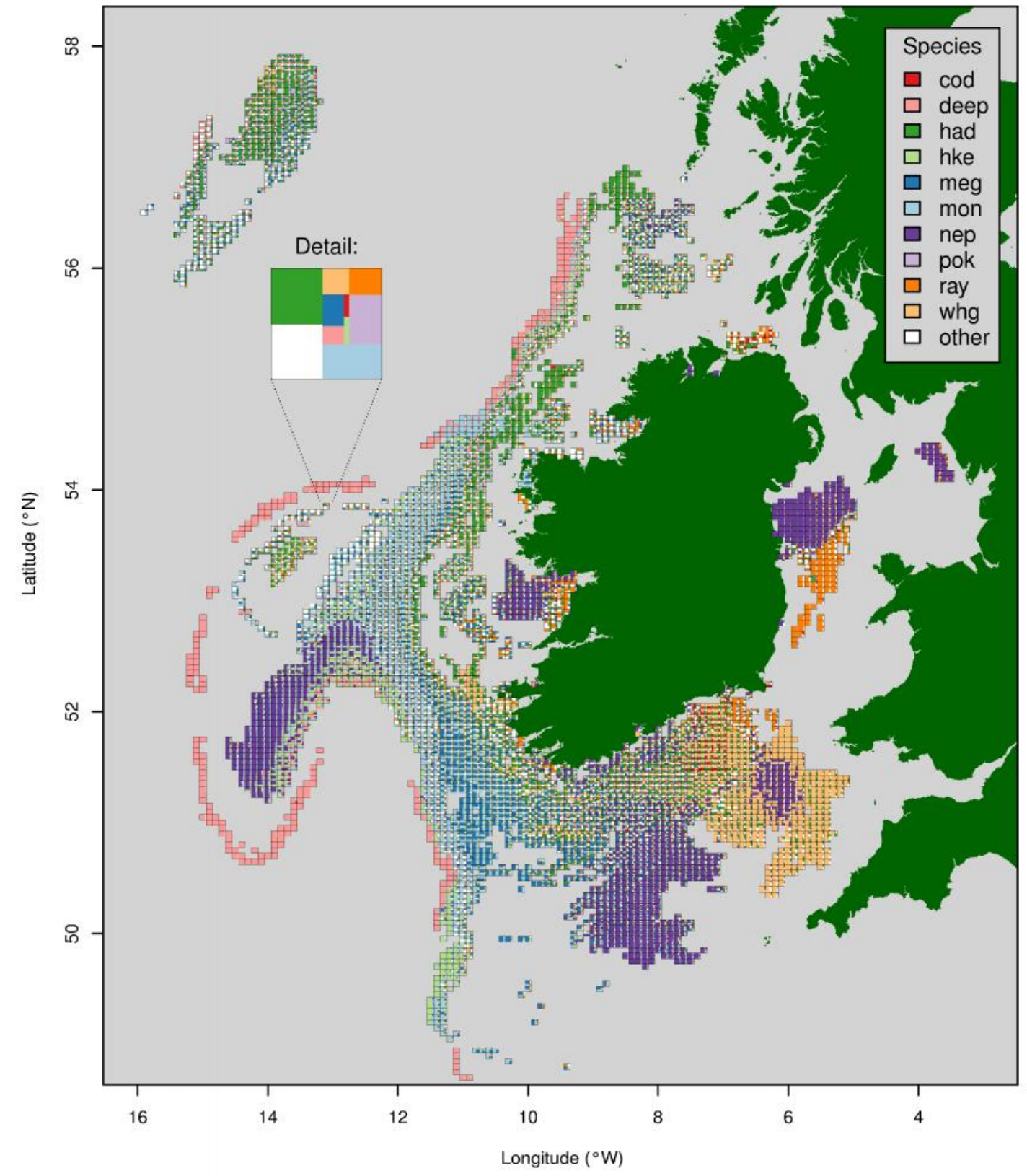

Figure 1. Species composition of the landings of Irish demersal otter trawlers during 2006-2009 in Irish and UK waters. Each grid cell contains a 2-dimensional barplot in which the area of each colour in the grid cell is proportional to the species composition by weight (similar to a pie chart; for more information on 2D barplots, see http://zoonek2.free.fr/UNIX/48_R/03.html ). The cells are $0.10^{\circ}$ longitude $* 0.05^{\circ}$ latitude in size. See Table 1 for species codes used in the legend. 


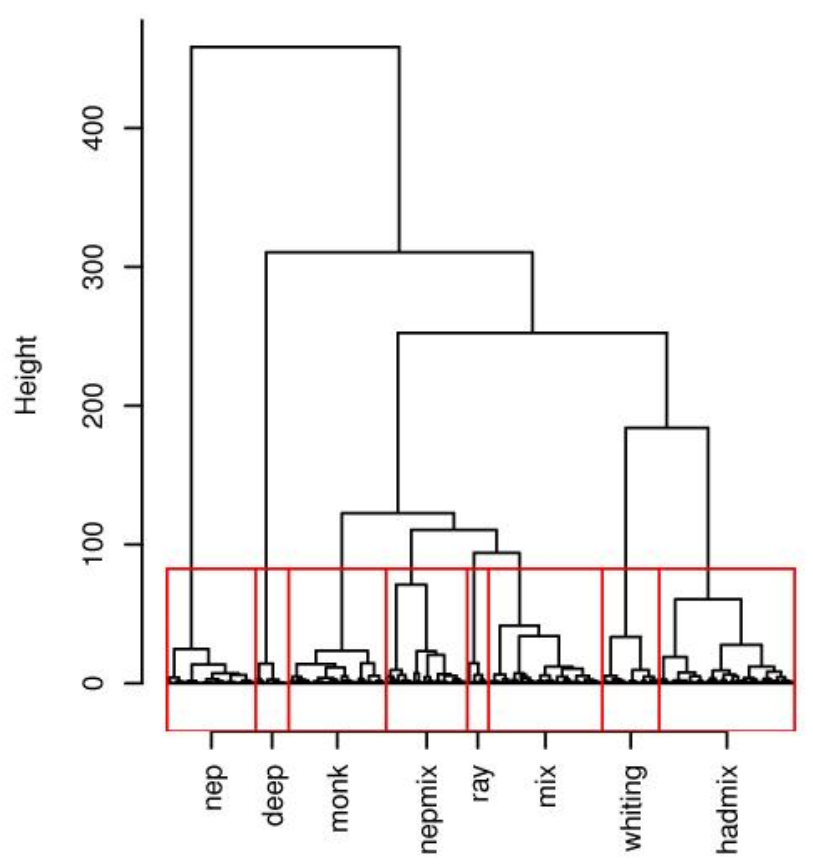

Figure 2. Dendrogram showing the clustering of the grid cells. The dendrogram was cut at a height that resulted in 8 clusters, represented by the rectangles. The names of the clusters are based on the dominant species or species mix in each cluster. 
(a)
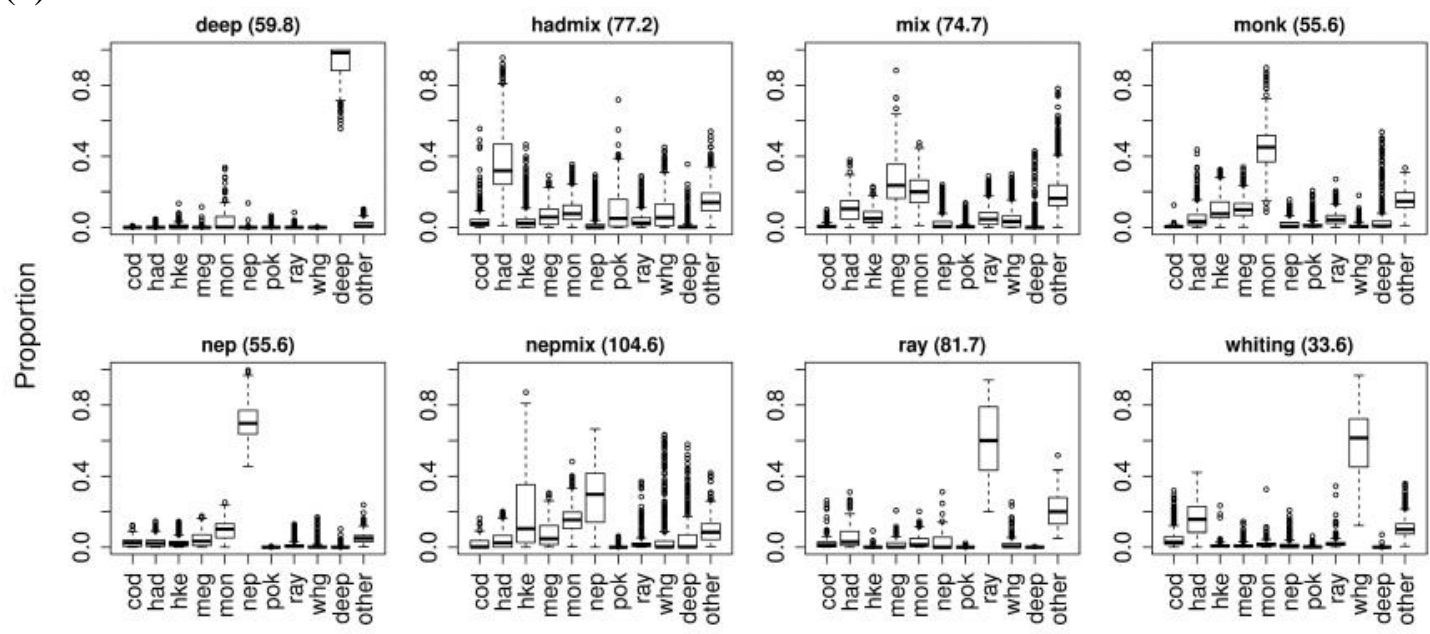

(b)
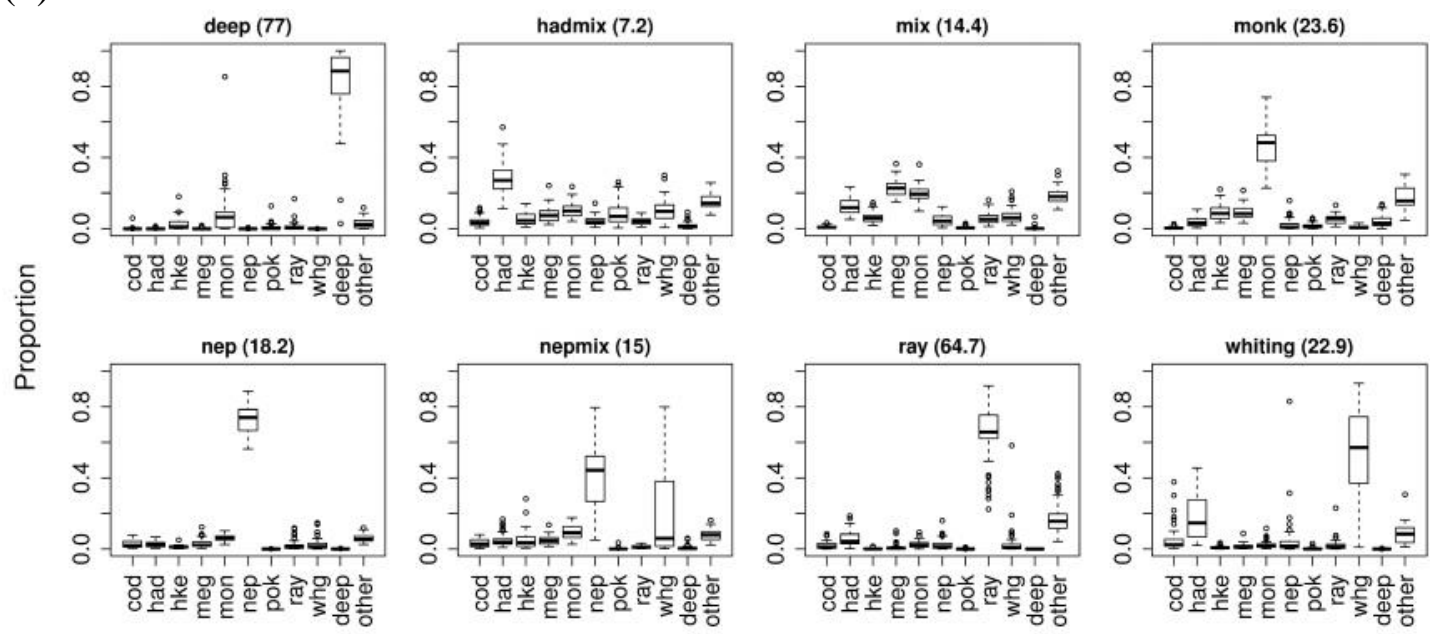

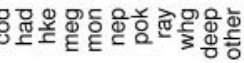

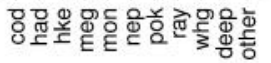

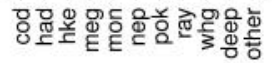

Figure 3 (a) The variability in the distribution of species composition between the grid cells and (b) between the months of the time-series in each of the 8 clusters. The total variability of the log-ratio transformed data is given in brackets. The boxes extend from the first to the third quartiles and the whiskers extend up to 1.5 times the interquartile range. See Table 1 for species codes used on the x-axis. 


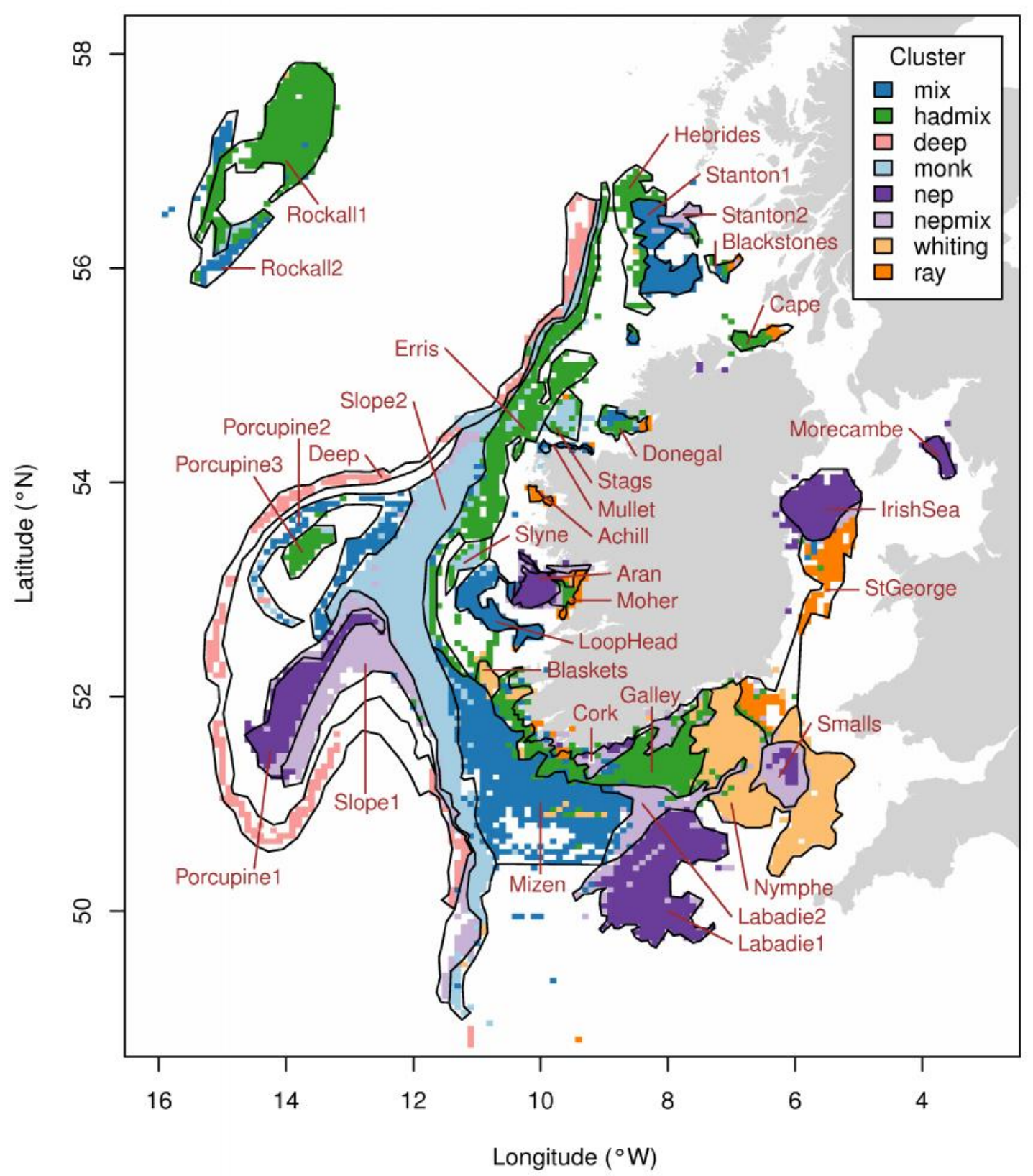

Figure 4. The spatial distribution of the grid cells assigned to 8 clusters; the colour of each pixel corresponds to the cluster it has been assigned to. The boundaries were drawn manually to define 34 regions. The regions were given names of fishing grounds or geographical features in order to identify them. 


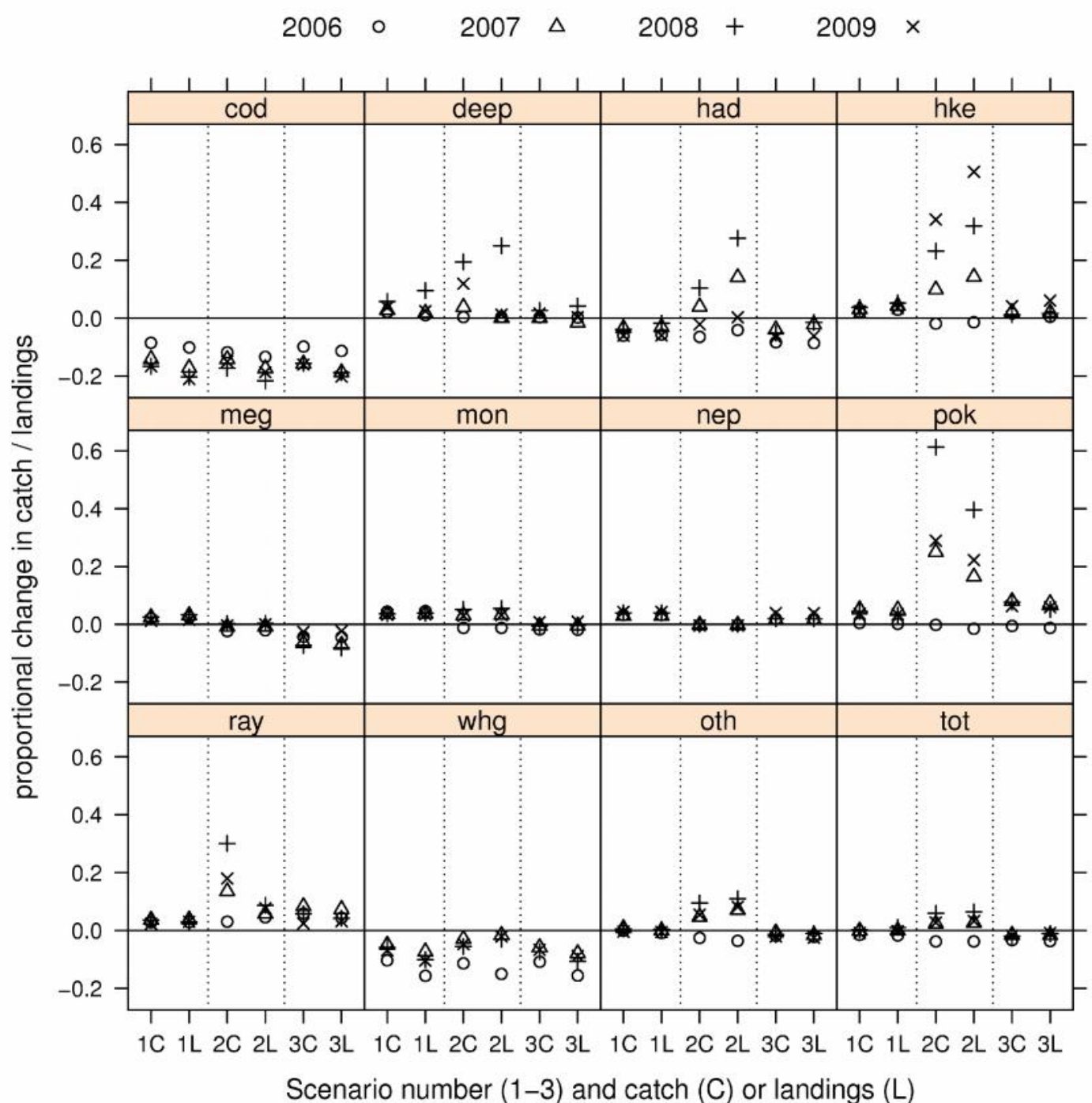

Figure 5. Proportional changes in the expected catch and landings if the Galley and Nymphe regions would have been closed during the first quarter of the year (the various symbols correspond to the years 2006-9). The $\mathrm{x}$-axis shows the scenario number (1-3) and whether the values relate to catch (C) or landings (L). I.e. "1C" relates to the catch data under scenario 1 . See Table 1 for species codes indicated above each panel. 